\title{
The APUS Supernova Search Program: A Scientific Leadership and Research Opportunity for Graduate and Undergraduate Students
}

\author{
Kristen A. Miller ${ }^{a \star}$, Christopher Colvina, Melanie Crowson ${ }^{\mathrm{b}}$, Jason \\ Cushard $^{\mathrm{a}}$, Terry Trevino ${ }^{\mathrm{a}}$ \\ a Department of Space Studies, The American Public University System, 111 West Congress Street, \\ Charles Town, West Virginia, USA 25414, space@apus.edu \\ ${ }^{b}$ Pisgah Astronomical Research Institute, 1 Pari Dr., Rosman, NC 28772, research@pari.edu \\ * Corresponding Author
}

\begin{abstract}
Providing hands-on learning experiences for students in space-related education programs is a challenge and particularly so for programs that are offered $100 \%$ online. The American Public University System (APUS) offers Bachelor of Science and Master of Science degree programs in Space Studies that are delivered completely online. To date, 559 graduate students and 405 undergraduate students from around the globe have completed degrees since the inception of our program. The unique aspect of our program is its emphasis on the use of astronomical observations to provide opportunities for students to participate in authentic research opportunities and to develop instrumentation for their research. APUS operates a 24-inch Planewave robotic telescope fitted with an SBIG STX-16803 charge-couple device camera, located in Charles Town, West Virginia. This instrument is an integral component of the undergraduate and graduate education in space studies that we provide. Currently, we use this instrument in a supernova search program where students process images of several dozen galaxies obtained from a periodic survey of the sky and then compare the observations to reference images using blink-comparison software. This program is an excellent research opportunity for both graduate and undergraduate space studies students. Students in the leadership group research, design, and test components of the supernova search program; under faculty direction, they engage in evaluating software and supervise small groups of students who analyze and study the images as they search for possible supernova events. This opportunity supports their classroom learning and provides a means for all students in the program to participate in
\end{abstract}


meaningful scientific research. Currently, 177 galaxies in six different regions of the sky are regularly observed in this program.

Keywords: supernova, online education, graduate research

\section{El programa de búsqueda de supernovas de APUS: un liderazgo científico y una oportunidad de investigación para estudiantes de posgrado y pregrado}

\section{RESUMEN}

Proporcionar experiencias prácticas de aprendizaje a los estudiantes en los programas de educación relacionados con el espacio es un desafío y especialmente para los programas que se ofrecen 100\% en línea. El Sistema Universitario Público Estadounidense (APUS) ofrece programas de licenciatura y maestría en estudios espaciales que se imparten completamente en línea. Hasta la fecha, 559 estudiantes graduados y 405 estudiantes universitarios de todo el mundo han completado sus títulos desde el inicio de nuestro programa. El aspecto único de nuestro programa es su énfasis en el uso de observaciones astronómicas para brindar oportunidades para que los estudiantes participen en oportunidades de investigación auténticas y para desarrollar instrumentación para su investigación. APUS opera un telescopio robótico Planewave de 24 pulgadas equipado con una cámara de dispositivo de carga-par SBIG STX-16803, ubicado en Charles Town, Virginia Occidental. Este instrumento es un componente integral de la educación de pregrado y posgrado en estudios espaciales que brindamos. Actualmente usamos este instrumento en un programa de búsqueda de supernovas donde los estudiantes procesan imágenes de varias docenas de galaxias obtenidas de un estudio periódico del cielo y luego comparan las observaciones con imágenes de referencia utilizando un software de comparación de parpadeos. Este programa es una excelente oportunidad de investigación para estudiantes de estudios espaciales de posgrado y pregrado. Los estudiantes del grupo de liderazgo investigan, diseñan y prueban componentes del programa de búsqueda de supernovas; bajo la dirección de la facultad, se involucran en la evaluación de software y supervisan a pequeños grupos de estudiantes que analizan y estudian las imágenes mientras buscan posibles eventos de supernovas. Esta oportunidad apoya su aprendizaje en el aula y proporciona un medio para que todos los estudiantes del programa participen en una investigación 
científica significativa. Actualmente, 177 galaxias en seis regiones diferentes del cielo se observan regularmente en este programa.

Palabras clave: supernova, educación en línea, investigación de posgrado

美国公立大学系统（APUS）超新星搜索项目：一项 针对研究生和本科生的科学领导力及研究机遇

\section{摘要}

为太空相关教育专业的学生提供实践学习体验是具有挑战性 的, 对那些完全提供线上教学的专业而言尤为如此。美国公 立大学系统 (APUS) 为太空研究专业的本科生及研究生提 供全线上教学。自该专业成立以来, 全球已有559名研究生 和 405 名本科生获得了相关学位。该专业的独特点在于其聚 焦于使用宇航观察来为学生提供机遇, 参与真实项目并为其 研究提供一系列工具。APUS操作一个24英寸的Planewave机 器望远镜, 搭配一个SBIG STX-16803型号的CCD相机, 该设 备位于西弗吉尼亚州查尔斯镇。该设备是我们所提供的太空 研究本科专业及研究生专业的一部分。目前我们在一项超新 星搜索项目中使用该设备, 其中学生对从关于太空的周期性 检验中获得的几十个星系图像进行处理, 随后使用闪视比较 软件（blink-comparison software）将观察发现与参考图像进 行比较。该项目对太空专业本科生及研究生而言是一次绝佳 的研究机遇。领导力小组中的学生对超新星搜索项目的各部 分进行研究、设计和测试; 在教师的指导下, 他们参与评价 软件并监督学生小组, 后者一边搜索可能的超新星事件, 一 边分析和研究图像。这一机遇促进了学生的课堂学习, 并为 该专业的所有学生提供途径参与有意义的科学研究。目前, 该项目对太空中 6 个不同区域里的177个星系进行定期观察。

关键词：超新星, 网络教育, 研究生研究 


\section{Acronyms/Abbreviations}

The following acronyms/abbreviations are used in this paper: Corrected Dall-Kirkham 24 inch (CDK24) telescope; charge-coupled device (CCD) camera; American Public University System (APUS); the Panoramic Survey Telescope and Rapid Response system (PanSTARRS1); the Public ESO Spectroscopic Survey of Transient Objects (PESSTO); Backyard observatory supernova search (BOSS); American Public University System Search for Supernovae (APUS SSN); Puckett Observatory Supernova Search (POSS); Chilean Automatic Supernova Search (CHASE); Lick Observatory Nearby Galaxy Supernova Search (NGSS); Luminous - red - green - blue (LRGB) filters; European Space Agency (ESA); Data Verification Analyst (DVA).

\section{Objective}

$\mathrm{T}$

o discuss the unique aspects of the APUS SSN program with an emphasis on the student run aspects of the program. To describe the successes of the program to date, and to suggest areas of improvement for the future.

\section{Introduction}

The purpose of this research program is two-fold: first and foremost, the purpose is to provide
APUS space studies students with the opportunity to develop leadership skills and gain relevant observational experience by creating and supervising a complex research program. The secondary purpose of the program is to document new supernova events throughout the universe to advance scientific knowledge in the community.

\subsection{Student Leadership}

It is common practice for graduate, and often even undergraduate, students to engage in formal research as part of their education. This is typically achieved by working with a faculty mentor. What is lacking in many STEM education programs, however, is the opportunity for students to take a lead role in the design of the research itself. Learning what is necessary to implement a successful research program is an invaluable experience that can set students apart from their peers in the field. This experience also directly translates to important career skills, better preparing students to be successful in future job opportunities.

\subsubsection{Hands-On Learning Opportunities}

Hands on learning activities have been shown to increase student interest and mastery in the sciences. Bloom's taxon- 
omy defines the highest level of thinking as that of "creation," which is the ability to "produce new or original work" [1]. Students who participate in original research programs at both the undergraduate and the graduate level thus have an opportunity to participate in the highest level of thinking/ learning.

\subsubsection{Supervisory Role}

Scientific research today is often performed as part of a group. Learning to navigate and lead in a group research project is a vital skill that will be increasingly important for science students looking to be competitive in the field. Students need to know how to work together to achieve meaningful results in research. The ability to organize group participation in a program, to motivate consistent and timely participation, to troubleshoot and resolve problems that arise, and to monitor results are invaluable skills in the scientific job market.

\subsection{Supernova Science}

Supernovae are highly violent events that release an enormous amount of energy over a very short period of time (astronomically speaking). There are two main types of supernovae; thermonuclear supernovae (Type I) are produced when material is accreted onto a white dwarf star from a companion star. When the mass of the white dwarf exceeds the Chandrasehkar limit, a supernova is the result. Core collapse supernovae are produced at the end of the life of a massive star and result from the implosion of the star's iron core. These include Type II, which keep their $\mathrm{H}$-rich envelopes prior to the explosion;
Type Ib, which lose their outer layers but retained their He-rich envelopes; and Type Ic, which lose both their $\mathrm{H}$ and He layers. Both types of supernovae produce roughly the same amount of energy over the same time period. Type I supernova have peak luminosities of about ten billion solar luminosities over a time period of a few weeks, while Type II supernovae peak at about one billion solar luminosities, but fade much more slowly [2]. The light curves and spectra differ for each type of supernova and represent an important identification tool after the initial detection is made. This study will search for both types of supernova without regard to the conditions that led to the event.

\subsubsection{Distance Measurements}

Supernovae are of interest in the astronomical community because their high luminosities make them easily to detect in even very distant galaxies. Because their peak luminosities and luminosity profiles are very well known, observations of distant supernovae can be used to very accurately determine the distances to their host galaxies. Thus, they are effective standard candles. Detecting and analyzing new supernovae events is thus highly important for the astronomical community.

\subsubsection{Discovery Statistics}

In a galaxy about the size of the Milky Way, it is estimated that one supernova explosion occurs roughly every 50 years [3]. If there are approximately 100 - 200 billion galaxies in the observable universe [4], this corresponds to roughly ten billion observable super- 
nova per year in the universe, or one per second.

\subsection{Current Programs}

There are currently several supernova search programs in existence in the astronomical community. These range from large scale, professionally funded efforts to small group studies to individuals, and even amateur astronomers. This paper will briefly describe the Supernova Hunters program, the Boss Team, CHASE, and the Lick Observatory NGSS, as well as the work of a few individuals to give an overview of the current state of the field.

\subsubsection{The Supernova Hunters Program}

The Supernova Hunters program is a citizen science supernova identification program [5]. This program uses the Zooniverse platform to search data from the Pan-STARRS1 all sky search database. Pan-STARRS1 scans the sky several times each month searching for transient objects (which includes supernovae). Zooniverse provides an interface for users to access and analyze this data; each observation is viewed and classified by multiple users before being flagged for further observation; this minimizes the statistical probability of erroneous "detections" from the Zooniverse user community, which consists almost entirely of untrained participants. Possible supernova candidates are further evaluated by the PESSTO team. Thus, the Supernova Hunters program represents a partnership between professional astronomers and the public in the search for supernova can- didates. To date, over 1 million classifications of transient objects (potential supernova candidates) have been made by nearly 6000 citizens. The program has identified 450 supernova candidates and 2 confirmed supernovae [6]. The program is currently paused while improvements to the analysis system are being made.

\subsubsection{The Boss Team}

The Boss Team is an Australia/New Zealand based group of amateur astronomers who work together to identify supernova candidates using personal telescopes. They supply data to the Central Bureau of Astronomical Telegrams, which is operated by the Harvard-Smithsonian Center for Astrophysics, for further observation and classification by professional astronomers. To date the BOSS team has identified nearly 200 potential supernova candidates, and has discovered more than 50 confirmed supernovae. [7]

\subsubsection{CHASE}

CHASE is a supernova search project that targets supernovae observations visible in the southern hemisphere. They use a group of 5 robotic $40 \mathrm{~cm}$ telescopes located on Cerro Tololo to observe 6,300 nearby galaxies on a regular basis (roughly 250 a night) using an 80 second exposure. [15] An automated calibration and comparison scheme allows the program to process the data nearly in real time. In their first four years of operation, they discovered 130 confirmed supernovae events. [15] 


\subsubsection{Lick NGSS}

The Lick NGSS program was one of the first programs to use CCD imaging and image-subtraction techniques to regularly observe a large sample of galaxies. NGSS observed a total of 14,882 galaxies over a period of 11 years, totaling millions of observations of galaxies and resulting in more than one thousand confirmed supernovae, spanning all supernovae types. [16]

\subsubsection{POSS}

POSS is a group of 18 amateur astronomers under the direction of founder Tim Puckett, an award-winning amateur astronomer and astro-photographer [8]. Team members are located around the world and work together to discover and verify supernova candidates. Since 1994, the POSS team has discovered over 270 supernovae.

\subsubsection{Individual Astronomers}

In addition to the programs described above, there are a number of individual astronomers, both professional and amateur, who also conduct supernova search programs. This paper will describe only one of particular note whose unique abilities have made him especially prominent in the field; however, there are many others. The most legendary supernova hunter is Australian amateur astronomer Robert Evens. In the 40 years he has been observing, Evens has discovered a total of 42 supernovae in his career using only a backyard telescope, paper, and a near perfect photographic memory of galactic star fields. He holds the record for visual discoveries of supernovae. [9]

\subsection{APUS SSN}

While there are many programs and individuals searching for supernovas, the APUS SSN program is unique in that it is performed entirely by graduate and undergraduate students (under faculty direction). Students in the leadership group design and oversee the working of the program, and both graduate and undergraduate students participate in the potential supernova candidate identification. This program thus represents a unique opportunity for students to participate in formal astronomical research. It also provides a means for students to develop valuable leadership skills in a scientific setting.

\section{Material and Methods}

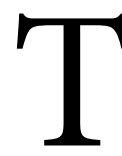

The methods described in this paper were originally developed through the work of APUS master's students Cary Hatch and Bradley Pellington, who each fulfilled the role of "project lead graduate student." The method has been updated and streamlined through the work of the current project leadership team, which consists of APUS students Christopher Colvin, Jason Cushard, and Terry Trevino, as well as Melanie Crowson, Director of Education at the PARI Research Institute and former project lead graduate student at APUS. Jason and Terry are the current project lead researchers; Christopher is our Data Verification Analyst (DVA), and Melanie provides observational support and follow up observations for any transients identified. These individuals will hereafter be referred to as the "leadership team." 


\subsection{The APUS Telescope}

APUS owns and operates a research grade telescope for faculty and student use. The telescope is housed in a fully automated 22.5' hemisphere dome on top of the Information Technology building on the APUS campus in Charles Town, $\mathrm{WV}$, elevation $170 \mathrm{~m}$. The telescope is a planewave CDK24, with an aperture of 24 inches and focal length of 155.98 inches. The focal ratio is $\mathrm{f} / 6.5$. It is paired with a 16.8 -megapixel SBIG STX-16803 CCD camera; the array size is $4096 \mathrm{x}$ 4096. It is also equipped with an SBIG FW-7 LRGB filter wheel. The telescope is fully robotic, able to be operated completely remotely, and can incorporate autonomous scripts.

\subsection{Galaxies Observed}

The galaxies observed in this project were chosen from 6 different regions of the sky. The chosen regions are designed to rise successively over the course of the night. This maximizes the amount of observing time as well as making efficient use of the telescope resources. The galaxies include a range of type and viewing angle; all are $11^{\text {th }}$ magnitude or brighter. A total of one hundred and seventy-seven galaxies can be observed nightly. Specifically, twenty-six galaxies are observed from the Pegasus region, sixteen from the Camelopardus/ Eridanus region, thirty-seven from the Ursa Major region, twenty from the Leo/Hydra region, forty-two from the Virgo region, and thirty-six from the Coma Berenices/Canes Venatici region (see Appendix A for more details). The telescope is automated using the Orchestrate software in order to transition smoothly between observational regions over the course of the night.

\subsection{Observations}

The observations are 60 second exposures using a standard L filter. The data is then calibrated by subtracting dark frames, flat fields, and bias frames; this processing compensates for irregularities in the CCD itself. The short length of the exposure is sufficient to provide a reasonably good quality image of the host galaxy and can easily capture any supernova events due to their high luminosities. The methods have been tested and proven capable of detecting transient events with brightness as low as 16th magnitude in a 60 second exposure. Typical supernovae brightness is well above this limit, even several weeks after the occurrence of the initial event.

\subsection{Data Analysis}

Once the data has been obtained and calibrated, it is analyzed by students in the Space Studies program using a procedure developed by the leadership team. The basic procedure involves comparing the obtained galaxy images with reference images of each galaxy which have been observed using the APUS telescope with the same observational parameters. The comparison allows the students to determine if any transient events exist. Such events constitute potential supernova candidates and are flagged for further analysis.

\subsubsection{Blink Comparison Process}

The images are analyzed using the Aladin Software program. Each image is loaded into the program, along with the 
reference galaxy images. The observer then selects 5-6 stars in the data image and marks the same stars in the reference image. Aladin uses these reference points to properly align the images. A visual comparison is performed using a blink comparison method. Aladin generates a composite, animated image that "blinks" back and forth between the reference and observed images. Because they are so bright, supernova can be easily seen as the images blink. Space Studies students work in teams under the guidance of the lead researchers to perform this part of the process, which affords them the opportunity to work with real data, perform visual data analysis, and potentially be part of the discovery process. Students log transient objects for further study; these logs are monitored by the team leaders, and potential supernova candidates are recorded for review and further observations.

\subsubsection{Further Analysis}

Once a transient object has been identified and confirmed, the team leader reports to the DVA for further study. There are several possibilities that must be ruled out before a supernova discovery can be confirmed. These include CCD effects such as hot pixels, photon leaking from previous images, and changes in seeing. CCD effects can be easily eliminated by follow up observations of the galaxy. False positives can also result from observational effects such as cosmic rays, asteroids in the foreground of the observation, and detection of a variable star. These possibilities must be evaluated through the use of Astrometrica (for asteroid verifi- cation) and variable star catalogs before the detection can be confirmed. Finally, a potential supernova discovery must be double checked to ensure that the observation is not a previously discovered supernova event. Once these possibilities have been eliminated, the DVA reports the detection to the community for confirmation, and further observations can be made to determine the properties of the supernova.

\subsection{Faculty/Student Roles}

Faculty perform an important supporting role in the program. The faculty provide the reference images for the galaxy comparisons and create the scripting that allows automated observing of the different sky regions. All observations are made under faculty supervision, with the leadership team assisting. Faculty also perform further study of supernova candidates to confirm the discovery and collect data on the supernova event.

The leadership group participates actively in the design and operation of the project. Cary Hatch (M.S. 3/2019) designed the original evaluation process for the data-the programs and instructions for aligning the data files and for blinking the images. Bradley Pellington (M.S. 10/2019), built on Hatch's work by extending the instruction manual students use to participate in the program and by designing and implementing the interface that allows students to work with the images and provides accountability (see section 3.5.1). Pellington also completed beta testing of the program and initiated the research phase. The current leadership 
team has streamlined the analysis procedure by piloting the use of Aladin to combine the alignment and comparison stages of analysis (which were formally completed as part of a two-step process). The new procedure uses a single step to both align and compare the images, which has resulted in a significant increase in the speed and efficiency of the analysis process. The leadership team has also created an autonomous, self-paced training procedure for new member onboarding and has developed a formal procedure for analysis of potential transient detections.

The current leadership group has also pioneered the use of a team structure in the research project. Members of the leadership team each recruit, train, and supervise a small team of students as they work to analyze the observations. The teams report directly to the lead researchers, who monitor results and help troubleshoot any problems that arise during the analysis.

\subsubsection{Program Accountability}

In any research program that involves multiple participants, a key factor is accountability. Data must be processed quickly, and results communicated in a short time frame, in order to confirm and further study supernova candidates before they fade below detection limits.

In the APUS SSN program, accountability is the sole responsibility of the leadership team. These students are responsible for communicating with both faculty and student program participants to ensure that all images are processed in an orderly and timely fashion and that no data is overlooked. The leadership team monitors the progress of data through the analysis process and is the point of contact for any technical issues that arise. The leadership team must also communicate regularly with the faculty to ensure that potential supernova candidates are reported for future study.

To manage this process, the team designed an observatory Google Drive account to provide organization and easy access to the data. The drive includes separate folders for each stage of the process as well as a check-out sheet where students can record which data they are analysing and any transient objects in the data. The simplicity of the system is its greatest asset; it is user friendly and effective, easily monitored, and fairly maintenance free. This system has been an important factor in creating a program that runs smoothly and efficiently.

\section{Theory and Calculation}

I

$t$ is important to establish the feasibility of a long-term research program such as the APUS SSN. Two factors are of primary concern here: the probability of detection and the timeframe of detection. Both are pivotal in determining the projected success rate of the program.

\subsection{Probability of Detection}

The probability of detection relates to the likelihood that the current program will observe a supernova when it occurs. This probability depends on a balance between two key factors: the rate of supernovae in the Universe and the 
sample size of the galaxies observed in the program.

\subsubsection{Supernova Rate}

The number of supernovae which occur yearly in the Universe has been studied by many groups; it varies by supernova type as well as by galaxy type, mass, and even the wavelength of observation and the inclination of the observed galaxy. These rates have been established fairly accurately in recent years; here, we will rely on the measurements by the Lick NGSS program, which computed rates for samples of nearby (local) galaxies based on CCD imaging and modern imaging subtraction techniques for a sample of 1000 supernovae spanning Types Ia, Ibc, and II. [14]

The supernova rate in the Milky Way galaxy is a well-established rate. The Lick observatory NGSS program estimates this rate at $2.84 \pm 0.60$ $\mathrm{SNe}$ per century [14], a number which is consistent with published supernovae rates from other groups using a variety of techniques. They then calculated rates as a function of galaxy mass and supernova type for nearby galaxies. For our purposes, the volumetric rate averaged over early and late type galaxies is sufficient. They report volume rates of 0.301 (Type Ia), 0.258 (Type Ib,c) and 0.447 (Type II) in units of $\left(10^{-4} \mathrm{SN} \mathrm{Mpc}^{-}\right.$ $\left.{ }^{3} \mathrm{yr}^{-1}\right)$. [14] Our sample comprises a radius of approximately 19.8 ; assuming a spherical distribution, this gives a volume of roughly $32.5 \times 10^{4} \mathrm{Mpc}^{3}$. Thus, we can expect rates of $0.98 \mathrm{yr}^{-1}$ (Type Ia); $0.83 \mathrm{yr}^{-1}$ (Type Ib,c); $1.45 \mathrm{yr}^{-1}$ (Type II), or roughly 3 per year. Note that this assumes complete sampling of the galaxies in the volume, however.

In addition, a supernova event does not necessarily mean a detection. A more useful indication of potential success for our study is perhaps given by established detection rates from similar studies, normalized by the number of observers (telescopes used) and detection capability. Based on observational rates, an estimate of a 2-3 detections per year is reasonable [12]. For comparison, the POSS group reports roughly 15 - 20 supernova detections per year using two telescopes, while the BOSS team reports $9-15$ detections an average per year using 6 telescopes. $[7,8]$

\subsubsection{Sample Probability}

The number of galaxies regularly observed in the research program directly relates to the probability of detection; the larger the sample size, the more likely a detection will be made. The APUS SSN sample contains 177 galaxies in multiple regions of the sky. Assuming a conservative one observable event per year in given the sample volume, this implies roughly 4200 observations per detection. Observational success rates of similar programs report approximately 1 supernova detection per one thousand observations. [7] [8]

\subsection{Observational Timeframe}

Supernova peak very quickly and decay over a period of a few weeks to a few months, depending on the type of the supernova (see Fig. 1). 


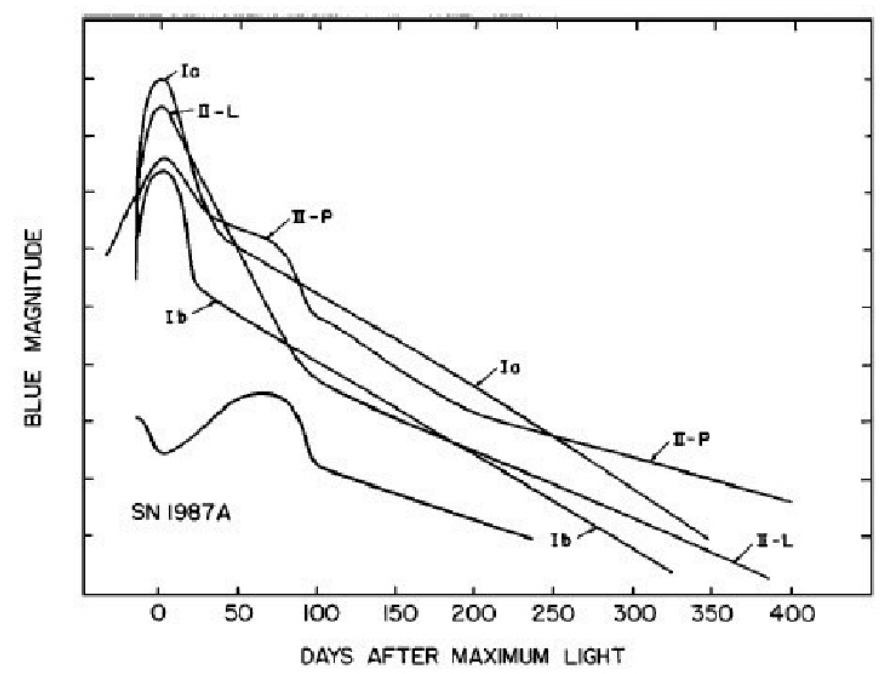

Fig. 1. Supernova lightcurves as a function of time. Image credit: Nadyozhin [13]

For galaxies of 11th magnitude or brighter, the APUS telescope is capable of detecting the light from a typical supernova for approximately 20 - 30 days. This means that each galaxy should be observed a minimum of twice a month in order to ensure that the event is still visible. Weekly observations are preferable in order to detect a supernova as quickly as possible after the event.

\section{Results}

he APUS SSN program has now
completed the testing phase and
is currently in operation.

\subsection{Testing Phase}

Under the direction of (then) lead graduate student Bradley Pellington, a group of two APUS Space Studies students participated in the testing phase of the SSN program from July 27, 2019 through August 4, 2019. The students analyzed 15 images using the process outlined in section 2 . The testing revealed that adjustments were needed in the instruction manual as well as an additional column for comments in the spreadsheet.

\subsection{Research Phase}

The SSN project is currently fully operational. Approximately 30 APUS Space Studies students are working under the supervision of the leadership team to analyze galaxy images and identify transient objects. Collectively, the students have analyzed hundreds of images at the time of this writing. Figures 2 and 3 show typical galaxy images from the SSN program. Both face-on and edge-on galaxy candidates are included in the galaxy sample.

A number of minor variations due to cosmic rays have been noted, and some photon leakage due to an exceptionally bright star in one of the images was reported. The group has confirmed detection of several transient 
events, including several asteroids and the identification of some known variable stars (Figure 4) as well as the detection of the previously reported May 6, 2020 supernova in M61, designation 2020jfo (Figure 5).
While not the supernovae discoveries hoped for, these detections indicate that the process is working. To date, no potential new supernovae candidates have been found, but progress is hopeful and on track for the future.

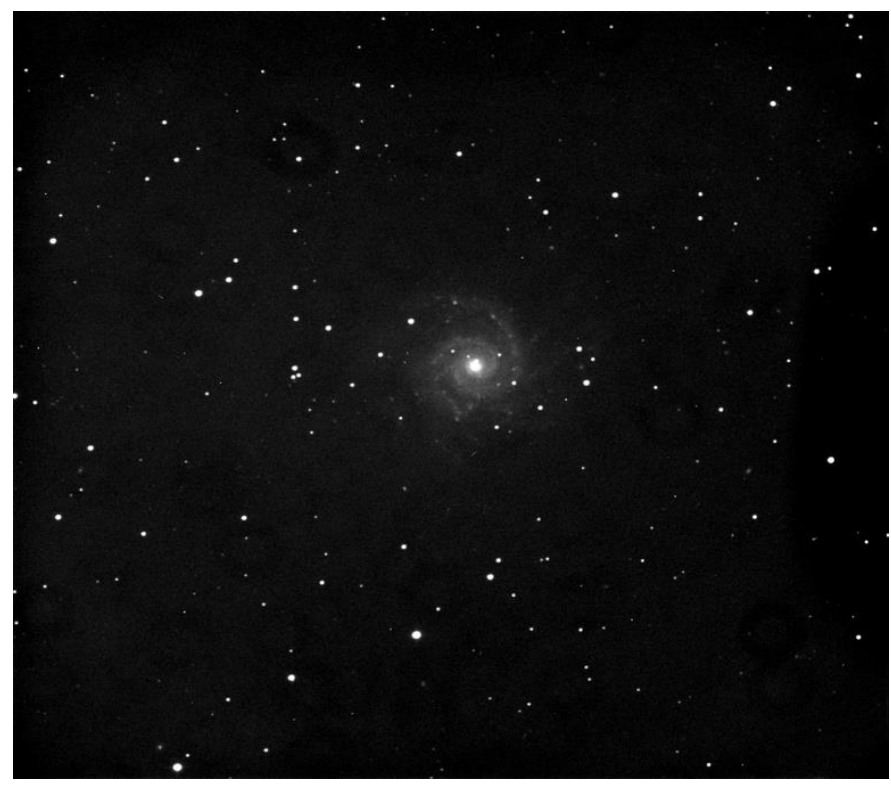

Fig. 2. NGC 628, Pegasus Region, APUS Observatory, June 2019. Image credit: K. Miller

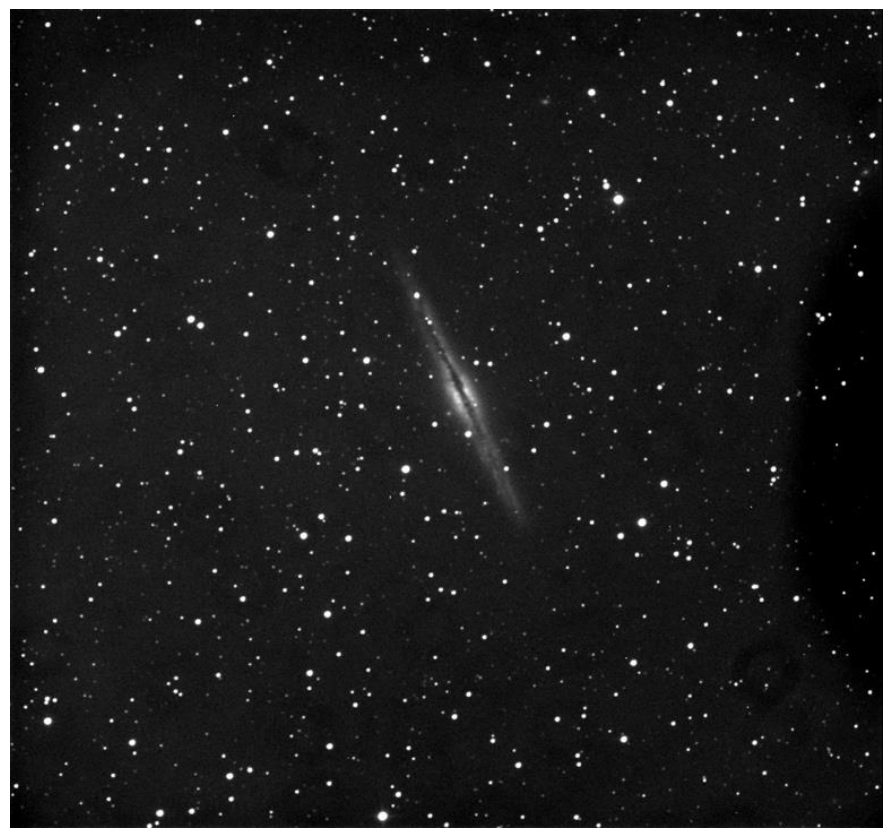

Fig. 3. NGC 891, Pegasus Region, APUS Observatory, June 2019. Image credit: K. Miller 


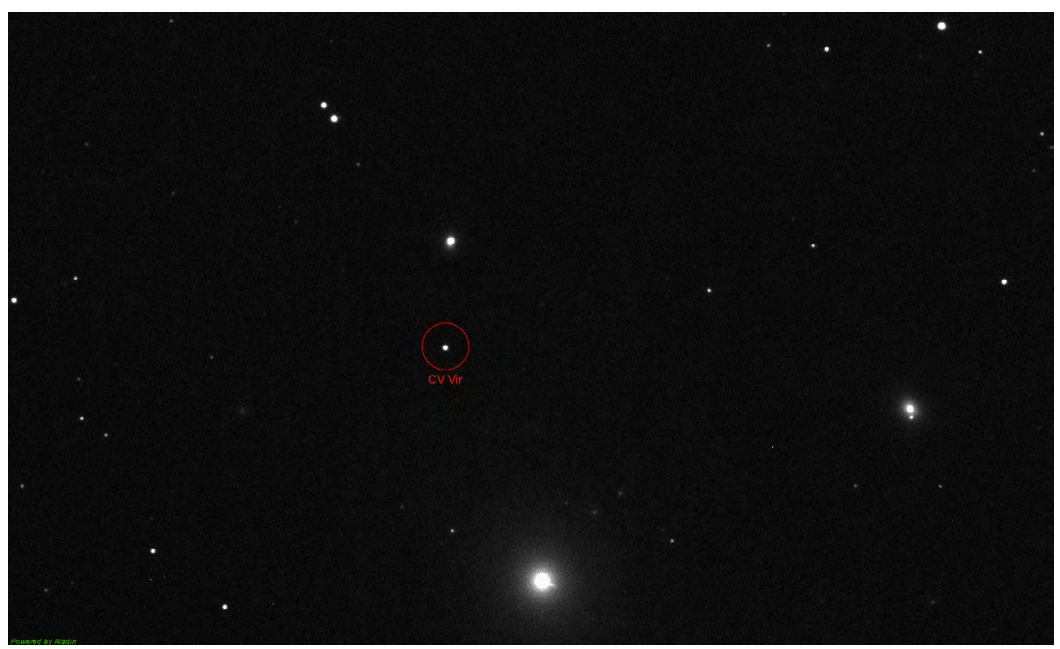

Figure 4: Detection of known variable star CV Vir. APUS Observatory, April 2020. Image credit: K. Miller

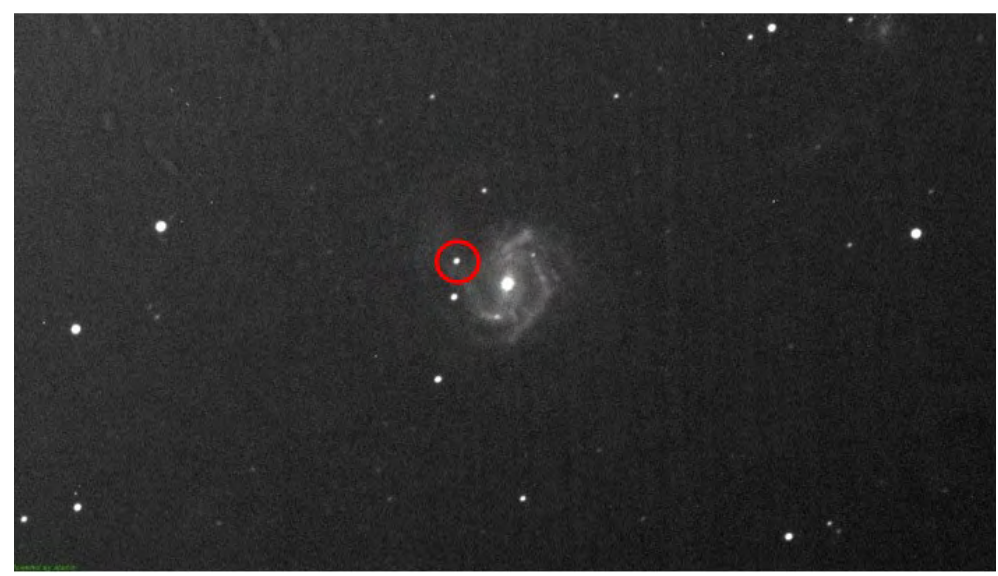

Figure 5: Detection of supernova 2020jfo in M61, APUS Observatory, May 2020. Image credit: K. Miller

\section{Discussion}

The main value of this program lies in the research opportunities afforded to both graduate and undergraduate students. Six APUS space studies students, from both the undergraduate and graduate programs, have gained the experience of developing a research program. The first lead student pioneered the development of programs that would work effectively in the APUS online environment. This work allowed the program to function remotely and smoothly. The second lead student completed testing of the program and developed the interface that allows students to participate in the program. The supervisory nature of his position provides a unique research experience. Both lead students also gained observational experience through the 
use of the APUS telescope to observe the galaxies in the program. The current leadership team has streamlined and improved the analysis procedure, developed an effective training program for students who join the research initiative, implemented a successful team-based approach, formalized the detection procedure, and supervised the transition from the testing to the research phase of the program. The combination of authentic observational and program management experience gives these students a unique advantage in future academic studies and also distinguishes them in the job market.

Space Studies students who choose to participate in the program also benefit greatly. Students have the opportunity to work with real observational data in fits format (the standard for astronomical imaging). They learn to analyze the images and detect transient features, which gives them experience in data interpretation. The hands-on nature of this experience is invaluable and particularly unique for students in an online university program.

\section{Conclusion}

7 his paper details the creation of a student run, faculty supported, 1 supernova search research program using the APUS 24-inch Planewave telescope. The program has been developed, tested, and successfully implemented by APUS Space Studies students, who direct both graduate and undergraduate students in analyzing the data. This program has the potential to contribute significantly to the scientific community through the detection of new supernova events. It also provides meaningful leadership opportunities for APUS graduate students, and authentic research experience for undergraduates.

\section{Acknowledgements}

The authors gratefully acknowledge APUS's commitment to excellence in both undergraduate and graduate online education, and the school's support of the Space Studies program through the purchase and maintenance of a dedicated, research grade telescope.

\section{Limitations and Bias}

This study is limited in the number of galaxies surveyed. The galaxy group represents an intentional bias towards nearby galaxies (high $\mathrm{Z}$ galaxies are excluded), primarily due to observational constraints. 


\section{Appendix A (List of Galaxies Observed)}

\begin{tabular}{|c|c|c|c|c|}
\hline Region & Galaxy & RA & Dec & Mag. \\
\hline Pegasus & NGC 7217 & $22^{\mathrm{h}} 07^{\mathrm{m}}$ & $31^{\circ} 21^{\prime}$ & 11 \\
\hline Pegasus & NGC 7331 & $22^{\mathrm{h}} 37^{\mathrm{m}}$ & $34^{\circ} 24^{\prime}$ & 10.4 \\
\hline Pegasus & NGC 7479 & $23^{\mathrm{h}} 04^{\mathrm{m}}$ & $12^{\circ} 19^{\prime}$ & 11.6 \\
\hline Pegasus & NGC 7640 & $23^{\mathrm{h}} 22^{\mathrm{m}}$ & $40^{\circ} 50^{\prime}$ & 11.1 \\
\hline Pegasus & NGC 224 & $00^{\mathrm{h}} 42^{\mathrm{m}}$ & $41^{\circ} 16^{\prime}$ & 3.44 \\
\hline Pegasus & NGC 488 & $01^{\mathrm{h}} 21^{\mathrm{m}}$ & $15^{\circ} 24^{\prime}$ & 10.4 \\
\hline Pegasus & NGC 598 & $01^{\mathrm{h}} 33^{\mathrm{m}}$ & $30^{\circ} 39^{\prime}$ & 5.72 \\
\hline Pegasus & NGC 628 & $01^{\mathrm{h}} 36^{\mathrm{m}}$ & $15^{\circ} 47^{\prime}$ & 10 \\
\hline Pegasus & NGC 672 & $01^{\mathrm{h}} 47^{\mathrm{m}}$ & $27^{\circ} 25^{\prime}$ & 11.5 \\
\hline Pegasus & NGC 772 & $01^{\mathrm{h}} 59^{\mathrm{m}}$ & $19^{\circ} 00^{\prime}$ & 10.3 \\
\hline Pegasus & NGC 891 & $02^{\mathrm{h}} 22^{\mathrm{m}}$ & $42^{\circ} 21^{\prime}$ & 10.8 \\
\hline Pegasus & NGC 925 & $02^{\mathrm{h}} 27^{\mathrm{m}}$ & $33^{\circ} 34^{\prime}$ & 10.7 \\
\hline Pegasus & NGC 7606 & $23^{\mathrm{h}} 19^{\mathrm{m}}$ & $-08^{\circ} 29^{\prime}$ & 10.8 \\
\hline Pegasus & NGC 7727 & $23^{\mathrm{h}} 39^{\mathrm{m}}$ & $-12^{\circ} 17^{\prime}$ & 11.5 \\
\hline Pegasus & NGC 45 & $00^{\mathrm{h}} 14^{\mathrm{m}}$ & $-23^{\circ} 10^{\prime}$ & 10.4 \\
\hline Pegasus & NGC 157 & $00^{\mathrm{h}} 34^{\mathrm{m}}$ & $-08^{\circ} 23^{\prime}$ & 10.4 \\
\hline Pegasus & NGC 247 & $00^{\mathrm{h}} 47^{\mathrm{m}}$ & $-20^{\circ} 45^{\prime}$ & 9.9 \\
\hline Pegasus & NGC 253 & $00^{\mathrm{h}} 47^{\mathrm{m}}$ & $-25^{\circ} 17^{\prime}$ & 8 \\
\hline Pegasus & NGC 578 & $01^{\mathrm{h}} 30^{\mathrm{m}}$ & $-22^{\circ} 40^{\prime}$ & 10.63 \\
\hline Pegasus & NGC 720 & $01^{\mathrm{h}} 53^{\mathrm{m}}$ & $-13^{\circ} 44^{\prime}$ & 10.2 \\
\hline Pegasus & NGC 908 & $02^{\mathrm{h}} 23^{\mathrm{m}}$ & $-21^{\circ} 14^{\prime}$ & 10.4 \\
\hline Pegasus & NGC 936 & $02^{\mathrm{h}} 27^{\mathrm{m}}$ & $-01^{\circ} 09^{\prime}$ & 10.2 \\
\hline Pegasus & NGC 1055 & $02^{\mathrm{h}} 41^{\mathrm{m}}$ & $00^{\circ} 26^{\prime}$ & 11.4 \\
\hline Pegasus & NGC 1068 & $02^{\mathrm{h}} 42^{\mathrm{m}}$ & $00^{\circ} 00^{\prime}$ & 9.61 \\
\hline Pegasus & NGC 1073 & $02^{\mathrm{h}} 43^{\mathrm{m}}$ & $01^{\circ} 22^{\prime}$ & 10.8 \\
\hline Pegasus & NGC 1087 & $02^{\mathrm{h}} 46^{\mathrm{m}}$ & $-00^{\circ} 29^{\prime}$ & 11.4 \\
\hline Cam/Eri & IC 342 & $03^{\mathrm{h}} 46^{\mathrm{m}}$ & $68^{\circ} 05^{\prime}$ & 9.1 \\
\hline Cam/Eri & NGC 1961 & $05^{\mathrm{h}} 42^{\mathrm{m}}$ & $69^{\circ} 22^{\prime}$ & 10.9 \\
\hline Cam/Eri & NGC 2146 & $06^{\mathrm{h}} 18^{\mathrm{m}}$ & $78^{\circ} 21^{\prime}$ & 11.38 \\
\hline Cam/Eri & NGC 2336 & $07^{\mathrm{h}} 27^{\mathrm{m}}$ & $80^{\circ} 10^{\prime}$ & 10.3 \\
\hline Cam/Eri & NGC 2403 & $07^{\mathrm{h}} 36^{\mathrm{m}}$ & $65^{\circ} 36^{\prime}$ & 8.9 \\
\hline Cam/Eri & NGC 2655 & $08^{\mathrm{h}} 55^{\mathrm{m}}$ & $78^{\circ} 13^{\prime}$ & 10.1 \\
\hline Cam/Eri & NGC 2683 & $08^{\mathrm{h}} 52^{\mathrm{m}}$ & $33^{\circ} 25^{\prime}$ & 10.6 \\
\hline
\end{tabular}




\begin{tabular}{|c|c|c|c|c|}
\hline Cam/Eri & NGC 1187 & $03^{\mathrm{h}} 02^{\mathrm{m}}$ & $-22^{\circ} 52^{\prime}$ & 11.4 \\
\hline Cam/Eri & NGC 1232 & $03^{\mathrm{h}} 09^{\mathrm{m}}$ & $-20^{\circ} 34^{\prime}$ & 10.9 \\
\hline Cam/Eri & NGC 1300 & $03^{\mathrm{h}} 19^{\mathrm{m}}$ & $-19^{\circ} 24^{\prime}$ & 11.4 \\
\hline Cam/Eri & NGC 1332 & $03^{\mathrm{h}} 26^{\mathrm{m}}$ & $-21^{\circ} 20^{\prime}$ & 7.05 \\
\hline Cam/Eri & NGC 1395 & $03^{\mathrm{h}} 38^{\mathrm{m}}$ & $-23^{\circ} 01^{\prime}$ & 9.8 \\
\hline Cam/Eri & NGC 1398 & $03^{\mathrm{h}} 38^{\mathrm{m}}$ & $-26^{\circ} 20^{\prime}$ & 10.63 \\
\hline Cam/Eri & NGC 1637 & $04^{\mathrm{h}} 41^{\mathrm{m}}$ & $-20^{\circ} 51^{\prime}$ & 11.5 \\
\hline Cam/Eri & NGC 1964 & $05^{\mathrm{h}} 33^{\mathrm{m}}$ & $-21^{\circ} 56^{\prime}$ & 10.8 \\
\hline Ursa Maj & NGC 2681 & $08^{\mathrm{h}} 53^{\mathrm{m}}$ & $51^{\circ} 18^{\prime}$ & 11.1 \\
\hline Ursa Maj & NGC 2841 & $09^{\mathrm{h}} 22^{\mathrm{m}}$ & $50^{\circ} 58^{\prime}$ & 10.1 \\
\hline Ursa Maj & NGC 2976 & $09^{\mathrm{h}} 47^{\mathrm{m}}$ & $67^{\circ} 54^{\prime}$ & 10.8 \\
\hline Ursa Maj & NGC 2985 & $09^{\mathrm{h}} 50^{\mathrm{m}}$ & $72^{\circ} 16^{\prime}$ & 10.4 \\
\hline Ursa Maj & NGC 3031 & $09^{\mathrm{h}} 55^{\mathrm{m}}$ & $69^{\circ} 03^{\prime}$ & 6.94 \\
\hline Ursa Maj & NGC 3034 & $09^{\mathrm{h}} 55^{\mathrm{m}}$ & $69^{\circ} 40^{\prime}$ & 8.41 \\
\hline Ursa Maj & NGC 3077 & $10^{\mathrm{h}} 03^{\mathrm{m}}$ & $68^{\circ} 44^{\prime}$ & 10.6 \\
\hline Ursa Maj & NGC 3184 & $10^{\mathrm{h}} 18^{\mathrm{m}}$ & $41^{\circ} 25^{\prime}$ & 10.4 \\
\hline Ursa Maj & NGC 3198 & $10^{\mathrm{h}} 19^{\mathrm{m}}$ & $45^{\circ} 32^{\prime}$ & 10.3 \\
\hline Ursa Maj & NGC 3310 & $10^{\mathrm{h}} 38^{\mathrm{m}}$ & $53^{\circ} 30^{\prime}$ & 11.2 \\
\hline Ursa Maj & NGC 3319 & $10^{\mathrm{h}} 39^{\mathrm{m}}$ & $41^{\circ} 41^{\prime}$ & 11.07 \\
\hline Ursa Maj & NGC 3359 & $10^{\mathrm{h}} 46^{\mathrm{m}}$ & $63^{\circ} 13^{\prime}$ & 10.57 \\
\hline Ursa Maj & NGC 3368 & $10^{\mathrm{h}} 46^{\mathrm{m}}$ & $11^{\circ} 49^{\prime}$ & 10.1 \\
\hline Ursa Maj & NGC 3556 & $11^{\mathrm{h}} 11^{\mathrm{m}}$ & $55^{\circ} 40^{\prime}$ & 10.7 \\
\hline Ursa Maj & NGC 3631 & $11^{\mathrm{h}} 21^{\mathrm{m}}$ & $53^{\circ} 10^{\prime}$ & 10.1 \\
\hline Ursa Maj & NGC 3675 & $11^{\mathrm{h}} 26^{\mathrm{m}}$ & $43^{\circ} 35^{\prime}$ & 10 \\
\hline Ursa Maj & NGC 3718 & $11^{\mathrm{h}} 32^{\mathrm{m}}$ & $53^{\circ} 04^{\prime}$ & 10.61 \\
\hline Ursa Maj & NGC 3726 & $11^{\mathrm{h}} 33^{\mathrm{m}}$ & $47^{\circ} 01^{\prime}$ & 10.2 \\
\hline Ursa Maj & NGC 3810 & $11^{\mathrm{h}} 40^{\mathrm{m}}$ & $11^{\circ} 28^{\prime}$ & 10.6 \\
\hline Ursa Maj & NGC 3893 & $11^{\mathrm{h}} 48^{\mathrm{m}}$ & $48^{\circ} 42^{\prime}$ & 10.2 \\
\hline Ursa Maj & NGC 3898 & $11^{\mathrm{h}} 49^{\mathrm{m}}$ & $56^{\circ} 05^{\prime}$ & 11.7 \\
\hline Ursa Maj & NGC 3938 & $11^{\mathrm{h}} 52^{\mathrm{m}}$ & $44^{\circ} 07^{\prime}$ & 10.9 \\
\hline Ursa Maj & NGC 3941 & $11^{\mathrm{h}} 52^{\mathrm{m}}$ & $36^{\circ} 59^{\prime}$ & 10.3 \\
\hline Ursa Maj & NGC 3953 & $11^{\mathrm{h}} 53^{\mathrm{m}}$ & $52^{\circ} 19^{\prime}$ & 10.8 \\
\hline Ursa Maj & NGC 3992 & $11^{\mathrm{h}} 57^{\mathrm{m}}$ & $53^{\circ} 22^{\prime}$ & 10.6 \\
\hline Ursa Maj & NGC 4051 & $12^{\mathrm{h}} 03^{\mathrm{m}}$ & $44^{\circ} 31^{\prime}$ & 12.92 \\
\hline Ursa Maj & NGC 4088 & $12^{\mathrm{h}} 05^{\mathrm{m}}$ & $50^{\circ} 32^{\prime}$ & 11.2 \\
\hline Ursa Maj & NGC 4125 & $12^{\mathrm{h}} 08^{\mathrm{m}}$ & $65^{\circ} 10^{\prime}$ & 10.7 \\
\hline
\end{tabular}




\begin{tabular}{|c|c|c|c|c|}
\hline Ursa Maj & NGC 4605 & $12^{\mathrm{h}} 39^{\mathrm{m}}$ & $61^{\circ} 36^{\prime}$ & 10.9 \\
\hline Ursa Maj & NGC 5322 & $13^{\mathrm{h}} 49^{\mathrm{m}}$ & $60^{\circ} 11^{\prime}$ & 10.1 \\
\hline Ursa Maj & NGC 5457 & $14^{\mathrm{h}} 03^{\mathrm{m}}$ & $54^{\circ} 20^{\prime}$ & 7.86 \\
\hline Ursa Maj & NGC 5474 & $14^{\mathrm{h}} 05^{\mathrm{m}}$ & $53^{\circ} 39^{\prime}$ & 11.3 \\
\hline Ursa Maj & NGC 5585 & $14^{\mathrm{h}} 19^{\mathrm{m}}$ & $56^{\circ} 43^{\prime}$ & 11.2 \\
\hline Ursa Maj & NGC 5866 & $15^{\mathrm{h}} 06^{\mathrm{m}}$ & $55^{\circ} 45^{\prime}$ & 10.7 \\
\hline Ursa Maj & NGC 5907 & $15^{\mathrm{h}} 15^{\mathrm{m}}$ & $56^{\circ} 19^{\prime}$ & 11.1 \\
\hline Ursa Maj & NGC 6503 & $17^{\mathrm{h}} 49^{\mathrm{m}}$ & $70^{\circ} 09^{\prime}$ & 10.2 \\
\hline Ursa Maj & NGC 6946 & $20^{\mathrm{h}} 34^{\mathrm{m}}$ & $60^{\circ} 09^{\prime}$ & 9.6 \\
\hline Leo/Hyd & NGC 2775 & $09^{\mathrm{h}} 10^{\mathrm{m}}$ & $07^{\circ} 02^{\prime}$ & 11.03 \\
\hline Leo/Hyd & NGC 2903 & $09^{\mathrm{h}} 32^{\mathrm{m}}$ & $21^{\circ} 30^{\prime}$ & 9.7 \\
\hline Leo/Hyd & NGC 3115 & $10^{\mathrm{h}} 05^{\mathrm{m}}$ & $-07^{\circ} 43^{\prime}$ & 9.9 \\
\hline Leo/Hyd & NGC 3166 & $10^{\mathrm{h}} 14^{\mathrm{m}}$ & $03^{\circ} 27^{\prime}$ & 7.21 \\
\hline Leo/Hyd & NGC 3338 & $10^{\mathrm{h}} 42^{\mathrm{m}}$ & $13^{\circ} 44^{\prime}$ & 12.1 \\
\hline Leo/Hyd & NGC 3344 & $10^{\mathrm{h}} 43^{\mathrm{m}}$ & $24^{\circ} 55^{\prime}$ & 10.5 \\
\hline Leo/Hyd & NGC 3351 & $10^{\mathrm{h}} 43^{\mathrm{m}}$ & $11^{\circ} 42^{\prime}$ & 11.4 \\
\hline Leo/Hyd & NGC 3377 & $10^{\mathrm{h}} 47^{\mathrm{m}}$ & $13^{\circ} 59^{\prime}$ & 10.2 \\
\hline Leo/Hyd & NGC 3379 & $10^{\mathrm{h}} 47^{\mathrm{m}}$ & $12^{\circ} 34^{\prime}$ & 10.2 \\
\hline Leo/Hyd & NGC 3486 & $11^{\mathrm{h}} 00^{\mathrm{m}}$ & $28^{\circ} 58^{\prime}$ & 10.5 \\
\hline Leo/Hyd & NGC 3489 & $11^{\mathrm{h}} 00^{\mathrm{m}}$ & $13^{\circ} 54^{\prime}$ & 10.2 \\
\hline Leo/Hyd & NGC 3521 & $11^{\mathrm{h}} 05^{\mathrm{m}}$ & $-00^{\circ} 02^{\prime}$ & 11 \\
\hline Leo/Hyd & NGC 3627 & $11^{\mathrm{h}} 20^{\mathrm{m}}$ & $12^{\circ} 59^{\prime}$ & 8.9 \\
\hline Leo/Hyd & NGC 3628 & $11^{\mathrm{h}} 20^{\mathrm{m}}$ & $13^{\circ} 36^{\prime}$ & 6.07 \\
\hline Leo/Hyd & NGC 2613 & $08^{\mathrm{h}} 33^{\mathrm{m}}$ & $-22^{\circ} 58^{\prime}$ & 11.6 \\
\hline Leo/Hyd & NGC 2835 & $09^{\mathrm{h}} 17^{\mathrm{m}}$ & $-22^{\circ} 21^{\prime}$ & 10.3 \\
\hline Leo/Hyd & NGC 3109 & $10^{\mathrm{h}} 03^{\mathrm{m}}$ & $-26^{\circ} 09^{\prime}$ & 10.4 \\
\hline Leo/Hyd & NGC 3923 & $11^{\mathrm{h}} 51^{\mathrm{m}}$ & $-28^{\circ} 48^{\prime}$ & 9.6 \\
\hline Leo/Hyd & NGC 4038 & $12^{\mathrm{h}} 01^{\mathrm{m}}$ & $-18^{\circ} 52^{\prime}$ & 11.2 \\
\hline Leo/Hyd & NGC 5236 & $13^{\mathrm{h}} 37^{\mathrm{m}}$ & $-29^{\circ} 51^{\prime}$ & 7.54 \\
\hline Virgo & NGC 4030 & $12^{\mathrm{h}} 00^{\mathrm{m}}$ & $-01^{\circ} 05^{\prime}$ & 10.6 \\
\hline Virgo & NGC 4216 & $12^{\mathrm{h}} 15^{\mathrm{m}}$ & $13^{\circ} 08^{\prime}$ & 11 \\
\hline Virgo & NGC 4261 & $12^{\mathrm{h}} 19^{\mathrm{m}}$ & $05^{\circ} 49^{\prime}$ & 11.4 \\
\hline Virgo & NGC 4303 & $12^{\mathrm{h}} 21^{\mathrm{m}}$ & $04^{\circ} 28^{\prime}$ & 10.18 \\
\hline Virgo & NGC 4365 & $12^{\mathrm{h}} 24^{\mathrm{m}}$ & $07^{\circ} 19^{\prime}$ & 6.64 \\
\hline Virgo & NGC 4374 & $12^{\mathrm{h}} 25^{\mathrm{m}}$ & $12^{\circ} 53^{\prime}$ & 10.1 \\
\hline Virgo & NGC 4429 & $12^{\mathrm{h}} 27^{\mathrm{m}}$ & $11^{\circ} 06^{\prime}$ & 11.02 \\
\hline
\end{tabular}




\begin{tabular}{|c|c|c|c|c|}
\hline Virgo & NGC 4438 & $12^{\mathrm{h}} 27^{\mathrm{m}}$ & $13^{\circ} 00^{\prime}$ & 10 \\
\hline Virgo & NGC 4442 & $12^{\mathrm{h}} 15^{\mathrm{m}}$ & $13^{\circ} 08^{\prime}$ & 11.2 \\
\hline Virgo & NGC 4472 & $12^{\mathrm{h}} 29^{\mathrm{m}}$ & $08^{\circ} 00^{\prime}$ & 9.4 \\
\hline Virgo & NGC 4477 & $12^{\mathrm{h}} 30^{\mathrm{m}}$ & $13^{\circ} 38^{\prime}$ & 11.38 \\
\hline Virgo & NGC 4486 & $12^{\mathrm{h}} 30^{\mathrm{m}}$ & $12^{\circ} 23^{\prime}$ & 9.59 \\
\hline Virgo & NGC 4517 & $12^{\mathrm{h}} 32^{\mathrm{m}}$ & $00^{\circ} 06^{\prime}$ & 10.6 \\
\hline Virgo & NGC 4526 & $12^{\mathrm{h}} 34^{\mathrm{m}}$ & $07^{\circ} 41^{\prime}$ & 10.7 \\
\hline Virgo & NGC 4527 & $12^{\mathrm{h}} 34^{\mathrm{m}}$ & $02^{\circ} 39^{\prime}$ & 11.4 \\
\hline Virgo & NGC 4535 & $12^{\mathrm{h}} 34^{\mathrm{m}}$ & $08^{\circ} 11^{\prime}$ & 7.38 \\
\hline Virgo & NGC 4536 & $12^{\mathrm{h}} 34^{\mathrm{m}}$ & $02^{\circ} 11^{\prime}$ & 11.1 \\
\hline Virgo & NGC 4552 & $12^{\mathrm{h}} 35^{\mathrm{m}}$ & $12^{\circ} 33^{\prime}$ & 10.73 \\
\hline Virgo & NGC 4569 & $12^{\mathrm{h}} 36^{\mathrm{m}}$ & $13^{\circ} 09^{\prime}$ & 10.26 \\
\hline Virgo & NGC 4579 & $12^{\mathrm{h}} 54^{\mathrm{m}}$ & $-10^{\circ} 14^{\prime}$ & 10.5 \\
\hline Virgo & NGC 4594 & $12^{\mathrm{h}} 39^{\mathrm{m}}$ & $-11^{\circ} 37^{\prime}$ & 8.98 \\
\hline Virgo & NGC 4621 & $12^{\mathrm{h}} 42^{\mathrm{m}}$ & $11^{\circ} 38^{\prime}$ & 10.6 \\
\hline Virgo & NGC 4636 & $12^{\mathrm{h}} 42^{\mathrm{m}}$ & $02^{\circ} 41^{\prime}$ & 9.4 \\
\hline Virgo & NGC 4649 & $12^{\mathrm{h}} 43^{\mathrm{m}}$ & $11^{\circ} 33^{\prime}$ & 9.8 \\
\hline Virgo & NGC 4654 & $12^{\mathrm{h}} 43^{\mathrm{m}}$ & $13^{\circ} 07^{\prime}$ & 12 \\
\hline Virgo & NGC 4665 & $12^{\mathrm{h}} 45^{\mathrm{m}}$ & $03^{\circ} 03^{\prime}$ & 10.3 \\
\hline Virgo & NGC 4666 & $12^{\mathrm{h}} 42^{\mathrm{m}}$ & $-00^{\circ} 11^{\prime}$ & 10.8 \\
\hline Virgo & NGC 4697 & $12^{\mathrm{h}} 48^{\mathrm{m}}$ & $-05^{\circ} 48^{\prime}$ & 9.2 \\
\hline Virgo & NGC 4699 & $12^{\mathrm{h}} 49^{\mathrm{m}}$ & $-08^{\circ} 39^{\prime}$ & 9.6 \\
\hline Virgo & NGC 4731 & $12^{\mathrm{h}} 48^{\mathrm{m}}$ & $-06^{\circ} 23^{\prime}$ & 10.5 \\
\hline Virgo & NGC 4753 & $12^{\mathrm{h}} 52^{\mathrm{m}}$ & $-01^{\circ} 11^{\prime}$ & 10.85 \\
\hline Virgo & NGC 4762 & $12^{\mathrm{h}} 52^{\mathrm{m}}$ & $11^{\circ} 13^{\prime}$ & 11.12 \\
\hline Virgo & NGC 4856 & $12^{\mathrm{h}} 54^{\mathrm{m}}$ & $-10^{\circ} 14^{\prime}$ & 10.72 \\
\hline Virgo & NGC 4939 & $13^{\mathrm{h}} 04^{\mathrm{m}}$ & $-10^{\circ} 20^{\prime}$ & 11.3 \\
\hline Virgo & NGC 5054 & $13^{\mathrm{h}} 16^{\mathrm{m}}$ & $-16^{\circ} 38^{\prime}$ & 10.36 \\
\hline Virgo & NGC 5068 & $13^{\mathrm{h}} 18^{\mathrm{m}}$ & $-21^{\circ} 02^{\prime}$ & 10.5 \\
\hline Virgo & NGC 5247 & $13^{\mathrm{h}} 38^{\mathrm{m}}$ & $-17^{\circ} 53^{\prime}$ & 10.5 \\
\hline Virgo & NGC 5248 & $13^{\mathrm{h}} 37^{\mathrm{m}}$ & $08^{\circ} 53^{\prime}$ & 10.97 \\
\hline Virgo & NGC 5364 & $13^{\mathrm{h}} 56^{\mathrm{m}}$ & $05^{\circ} 00^{\prime}$ & 11.2 \\
\hline Virgo & NGC 5566 & $14^{\mathrm{h}} 20^{\mathrm{m}}$ & $03^{\circ} 56^{\prime}$ & 11.1 \\
\hline Virgo & NGC 5746 & $14^{\mathrm{h}} 44^{\mathrm{m}}$ & $01^{\circ} 57^{\prime}$ & 11 \\
\hline Virgo & NGC 5846 & $15^{\mathrm{h}} 06^{\mathrm{m}}$ & $01^{\circ} 36^{\prime}$ & 10.1 \\
\hline $\mathrm{CB} / \mathrm{CV}$ & NGC 4192 & $12^{\mathrm{h}} 13^{\mathrm{m}}$ & $14^{\circ} 54^{\prime}$ & 11 \\
\hline
\end{tabular}




\begin{tabular}{|c|c|c|c|c|}
\hline $\mathrm{CB} / \mathrm{CV}$ & NGC 4254 & $12^{\mathrm{h}} 18^{\mathrm{m}}$ & $14^{\circ} 24^{\prime}$ & 10.4 \\
\hline $\mathrm{CB} / \mathrm{CV}$ & NGC 4274 & $12^{\mathrm{h}} 29^{\mathrm{m}}$ & $29^{\circ} 36^{\prime}$ & 10.4 \\
\hline $\mathrm{CB} / \mathrm{CV}$ & NGC 4293 & $12^{\mathrm{h}} 21^{\mathrm{m}}$ & $18^{\circ} 22^{\prime}$ & 10.4 \\
\hline $\mathrm{CB} / \mathrm{CV}$ & NGC 4314 & $12^{\mathrm{h}} 22^{\mathrm{m}}$ & $29^{\circ} 53^{\prime}$ & 11.4 \\
\hline $\mathrm{CB} / \mathrm{CV}$ & NGC 4321 & $12^{\mathrm{h}} 22^{\mathrm{m}}$ & $15^{\circ} 49^{\prime}$ & 9.5 \\
\hline $\mathrm{CB} / \mathrm{CV}$ & NGC 4382 & $12^{\mathrm{h}} 25^{\mathrm{m}}$ & $18^{\circ} 11^{\prime}$ & 10 \\
\hline $\mathrm{CB} / \mathrm{CV}$ & NGC 4414 & $12^{\mathrm{h}} 26^{\mathrm{m}}$ & $31^{\circ} 13^{\prime}$ & 11 \\
\hline $\mathrm{CB} / \mathrm{CV}$ & NGC 4450 & $12^{\mathrm{h}} 28^{\mathrm{m}}$ & $17^{\circ} 05^{\prime}$ & 10.9 \\
\hline $\mathrm{CB} / \mathrm{CV}$ & NGC 4459 & $12^{\mathrm{h}} 29^{\mathrm{m}}$ & $13^{\circ} 58^{\prime}$ & 11.32 \\
\hline $\mathrm{CB} / \mathrm{CV}$ & NGC 4494 & $12^{\mathrm{h}} 31^{\mathrm{m}}$ & $25^{\circ} 46^{\prime}$ & 9.7 \\
\hline $\mathrm{CB} / \mathrm{CV}$ & NGC 4501 & $12^{\mathrm{h}} 31^{\mathrm{m}}$ & $14^{\circ} 25^{\prime}$ & 10.4 \\
\hline $\mathrm{CB} / \mathrm{CV}$ & NGC 4548 & $12^{\mathrm{h}} 35^{\mathrm{m}}$ & $14^{\circ} 29^{\prime}$ & 11 \\
\hline $\mathrm{CB} / \mathrm{CV}$ & NGC 4559 & $12^{\mathrm{h}} 35^{\mathrm{m}}$ & $27^{\circ} 57^{\prime}$ & 10.4 \\
\hline $\mathrm{CB} / \mathrm{CV}$ & NGC 4565 & $12^{\mathrm{h}} 36^{\mathrm{m}}$ & $25^{\circ} 59^{\prime}$ & 10.42 \\
\hline $\mathrm{CB} / \mathrm{CV}$ & NGC 4725 & $12^{\mathrm{h}} 50^{\mathrm{m}}$ & $25^{\circ} 30^{\prime}$ & 10.1 \\
\hline $\mathrm{CB} / \mathrm{CV}$ & NGC 4826 & $12^{\mathrm{h}} 56^{\mathrm{m}}$ & $21^{\circ} 40^{\prime}$ & 9.36 \\
\hline $\mathrm{CB} / \mathrm{CV}$ & NGC 4145 & $12^{\mathrm{h}} 10^{\mathrm{m}}$ & $39^{\circ} 53^{\prime}$ & 11.3 \\
\hline $\mathrm{CB} / \mathrm{CV}$ & NGC 4151 & $12^{\mathrm{h}} 10^{\mathrm{m}}$ & $39^{\circ} 24^{\prime}$ & 11.5 \\
\hline $\mathrm{CB} / \mathrm{CV}$ & NGC 4214 & $12^{\mathrm{h}} 15^{\mathrm{m}}$ & $36^{\circ} 19^{\prime}$ & 10.2 \\
\hline $\mathrm{CB} / \mathrm{CV}$ & NGC 4236 & $12^{\mathrm{h}} 16^{\mathrm{m}}$ & $69^{\circ} 27^{\prime}$ & 10.5 \\
\hline $\mathrm{CB} / \mathrm{CV}$ & NGC 4242 & $12^{\mathrm{h}} 17^{\mathrm{m}}$ & $45^{\circ} 37^{\prime}$ & 11.37 \\
\hline $\mathrm{CB} / \mathrm{CV}$ & NGC 4244 & $12^{\mathrm{h}} 17^{\mathrm{m}}$ & $37^{\circ} 48^{\prime}$ & 7.72 \\
\hline $\mathrm{CB} / \mathrm{CV}$ & NGC 4258 & $12^{\mathrm{h}} 19^{\mathrm{m}}$ & $47^{\circ} 18^{\prime}$ & 8.4 \\
\hline $\mathrm{CB} / \mathrm{CV}$ & NGC 4395 & $12^{\mathrm{h}} 25^{\mathrm{m}}$ & $33^{\circ} 32^{\prime}$ & 10.6 \\
\hline $\mathrm{CB} / \mathrm{CV}$ & NGC 4395 & $12^{\mathrm{h}} 25^{\mathrm{m}}$ & $33^{\circ} 32^{\prime}$ & 10.6 \\
\hline $\mathrm{CB} / \mathrm{CV}$ & NGC 4449 & $12^{\mathrm{h}} 28^{\mathrm{m}}$ & $44^{\circ} 05^{\prime}$ & 10 \\
\hline $\mathrm{CB} / \mathrm{CV}$ & NGC 4490 & $12^{\mathrm{h}} 30^{\mathrm{m}}$ & $41^{\circ} 38^{\prime}$ & 9.8 \\
\hline $\mathrm{CB} / \mathrm{CV}$ & NGC 4618 & $12^{\mathrm{h}} 41^{\mathrm{m}}$ & $41^{\circ} 09^{\prime}$ & 11.2 \\
\hline $\mathrm{CB} / \mathrm{CV}$ & NGC 4656 & $12^{\mathrm{h}} 43^{\mathrm{m}}$ & $32^{\circ} 10^{\prime}$ & 11 \\
\hline $\mathrm{CB} / \mathrm{CV}$ & NGC 4736 & $12^{\mathrm{h}} 50^{\mathrm{m}}$ & $41^{\circ} 07^{\prime}$ & 8.99 \\
\hline $\mathrm{CB} / \mathrm{CV}$ & NGC 5005 & $13^{\mathrm{h}} 10^{\mathrm{m}}$ & $37^{\circ} 03^{\prime}$ & 10.6 \\
\hline $\mathrm{CB} / \mathrm{CV}$ & NGC 5033 & $13^{\mathrm{h}} 13^{\mathrm{m}}$ & $36^{\circ} 35^{\prime}$ & 10.8 \\
\hline $\mathrm{CB} / \mathrm{CV}$ & NGC 5055 & $13^{\mathrm{h}} 15^{\mathrm{m}}$ & $42^{\circ} 01^{\prime}$ & 9.3 \\
\hline $\mathrm{CB} / \mathrm{CV}$ & NGC 5194 & $13^{\mathrm{h}} 29^{\mathrm{m}}$ & $47^{\circ} 11^{\prime}$ & 8.4 \\
\hline $\mathrm{CB} / \mathrm{CV}$ & NGC 5371 & $13^{\mathrm{h}} 55^{\mathrm{m}}$ & $40^{\circ} 27^{\prime}$ & 11.3 \\
\hline
\end{tabular}




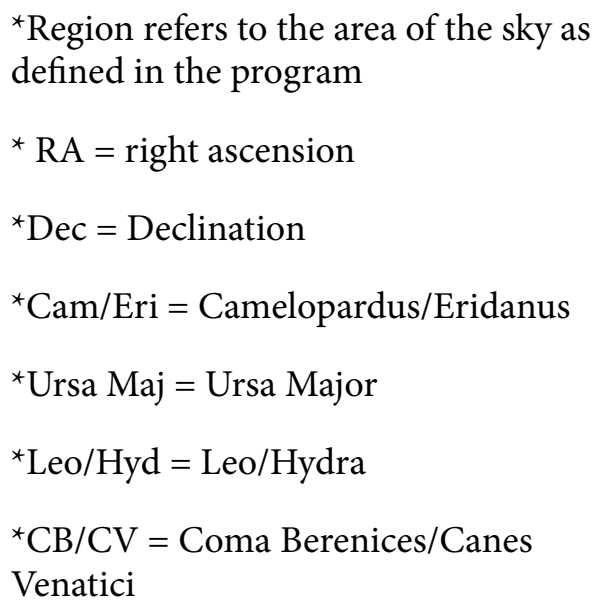

\section{References}

[1] J. M. Kouzes, B.Z. Posner, Leadership the Challenge, 3rd ed., Jossey-Bass, California 2002

[2] R. Nave, Type I and Type II Supernovae rate, http://hyperphysics.phy-astr.gsu. edu/hbase/Astro/snovcn.html,(accessed 22.08.19)

[3] R. Naeye, Milky Way Supernova Rate Confirmed, 2006, https://www.skyandtele scope.com/astronomy-news/milky-way-supernova-rate-confirmed/, (accessed 16. 08.2019)

[4] E. Howell, How Many Galaxies Are There? 2018, https://www.space.com/25303how-many-galaxies-are-in-the-universe.html, (accessed 05.08.2019)

[5] A.M. Smith, S. Lynne, M. Sullivan, C.J. Lintott, P.E. Nugent, J. Botyanszki, M. Kasliwal, R. Quimby, S.P. Bamford, L. Fortson, K. Schawinski, I. Hook, S. Blake, P. Podsiadlowski, J. Jonsson, A. Gal-Yam, I. Arcavi, D.A. Howell, J.S. BLoom, J. Jacobsen, R. Kulkarni, N.M. Law, E.O. Ofek, R. Walters, Galaxy Zoo Supernovae, M.N.R.A.S. 412 (2011), 1309-1319

[6] D.E. Wright, C.J. Lintott, S. J. Smartt, K.W. Smith, L. Fortson, L. Trouille, C.R. Allen, M. Beck, M.C. Bouslog, A. Boyer, K.C Chambers, H. Flewelling, W. Granger, E.A. Magnier, A. McMaster, G.R.M. Miller, J.E. O’Donnell, H. Spiers, J.L. Tonry, M. Veldthuis, R.J. Wainscoad, C. Waters, M. Willman, Z. Wolfenbarger, D.R. Young, A Transient Search Using Combined Human and Machine Classifications, 
M.N.R.A.S. 000 (2016), 1-10

[7] G. Bock, B. Downs, C. Drescher, P. Marples, S. Parker, P. Pearl, BOSS - Backyard Observatory Supernova Search, 2012, https://bosssupernova.com/, (accessed 15.06.19)

[8] T. Puckett, Puckett Observatory, 2018, http://www.cometwatch.com/home. html, (accessed 03.08.19)

[9]E. Aguirre, Supernova Champ Makes 40th Find, 2005, https://www.skyandtele scope.com/astronomy-news/supernova-champ-makes-40th-find/, (accessed 22. 08.19)

[10] E. Howell, How Many Galaxies Are There? 2018, https://www.space. com/25303-how-many-galaxies-are-in-the-universe.html, (accessed 20.08.19)

[11] N.T. Redd, What is a Spiral Galaxy? 2018, https://www.space.com/22382-spi ral-galaxy.html, (accessed 20.08.19)

[12] O. Graur, F.B. Bianco, M. Modjaz, A Unified Explanation for the Supernova Rate-Galaxy Mass Dependency Based on Supernovae Detected in Sloan Galaxy Spectra, M.N.R.A.S. 450 (2015), 905-925

[13] D. K. Nadyozhin, Physics of Supernovae: Theory, Observations, Unresolved Problems, Proceedings of the Baikal Young Scientists' International School (2007) $17-22$

[14] Leasman, H, Weidon, L, Chornock, R, Filippenko, A. Nearby supernova rates from the Lick Observatory Supernova Search - III The rate-size relation, and the rates as a function of galaxy Hubble type and colour, M.N.R.A.S 412 (2011), 1473 $-1507$

[15] Pignata, G, Maza, R A, Cartier, R, Folatelli, G, Forster, F, Conzalez, L, Gonzalez, P, Hamuy, M, Iturra, D, Lopez, P, Silva, S, Conuel, B, Crain, A, Foster, D, Ivarsen, K, LaClyze, A, Nysewander, M, Reichart, D, The CHilean Automatic Supernova sEarch (CHASE), API Conference Proceedings, 1111, 551 (2009)

[16] Weidon, L, Chornock, R, Leaman, J, Filippenko, A, Poznanski, D, Wang, X, Ganeshalingan, M, Mannucci, F, Nearby supernova rates from the Lick Observatory Supernova Search - III. The rate-size relation, and the rates as a function of galaxy Hubble type and colour, M.N.R.A.S., 412, 3 (2011), 1473 - 1507 


\section{Conflicts of Interest}

Preliminary reports of this project were made at the AAS Meeting 233 in January 8, 2019 and presented at the $70^{\text {th }}$ International Astronautical Congress, 21-25 October 2019, Washington, D.C., United States. A preliminary report of the project was published in the IAC proceedings, reference number IAC-19, E1,3,11,x54118 